A N N A L E S Annales de Bretagne et des Pays de l'Ouest

\title{
Tranvouez Yvon, La décomposition des chrétientés occidentales (1950-2010)
}

\section{Samuel Gicquel}

\section{(2) OpenEdition}

1 Journals

\section{Édition électronique}

URL : http://journals.openedition.org/abpo/3012

DOI : $10.4000 /$ abpo.3012

ISBN : 978-2-7535-4130-6

ISSN : 2108-6443

\section{Éditeur}

Presses universitaires de Rennes

Édition imprimée

Date de publication : 15 avril 2015

Pagination : 212-214

ISBN : 978-2-7535-4128-3

ISSN : 0399-0826

\section{Référence électronique}

Samuel Gicquel, «Tranvouez Yvon, La décomposition des chrétientés occidentales (1950-2010) 》, Annales de Bretagne et des Pays de l'Ouest [En ligne], 122-1 | 2015, mis en ligne le 15 avril 2015, consulté le 23 septembre 2020. URL : http://journals.openedition.org/abpo/3012 ; DOI : https://doi.org/10.4000/ abpo.3012 
Tranvouez, Yvon (dir.), La décomposition des chrétientés occidentales (1950-2010), Brest, CRBC-UBO, 2013, 388 p.

La décomposition des chrétientés occidentales est le second volet d'un triptyque consacré aux transformations du catholicisme dans ses forteresses d'Europe occidentale et d'Amérique du Nord depuis le milieu du $x^{e}$ siècle. Dans le sillage du colloque exploratoire organisé à Fribourg en 2011, vingt-trois historiens, sociologues et politistes se sont rassemblés à Brest les 31 mai et $1^{\text {er }}$ juin 2012 pour réfléchir à la déprise sociale de la religion catholique depuis les années 1950. C’est leurs communications qui sont rassemblées dans le présent ouvrage. "Décomposition des chrétientés occidentales»: le titre de ce recueil d'actes entre en résonance avec l'intitulé d'un autre travail collectif également coordonné par Yvon Tranvouez, Requiem pour le catholicisme breton ?, publié en 2011. Le vocabulaire ne doit pas tromper : les auteurs n'annoncent nullement la mort du catholicisme, mais analysent sa « décomposition », c'est-à-dire son recul, ses mutations ou, pour reprendre les mots introductifs d'Yvon Tranvouez, « l'effacement de la configuration sociale favorable qui a longtemps été celle de l’Église catholique » dans ce que le chanoine Boulard appelait les « bastions de chrétienté ».

Deux problématiques essentielles structurent le colloque et donc l'ouvrage. La première vise à affiner la connaissance des rythmes et des formes du détachement religieux. À l'exception de l'approche synthétique et globale de Gerd-Rainer Horn sur « les chrétientés catholiques à l'épreuve des sixties et des seventies », les communications s'enchaînent par paires et la dimension comparatiste souhaitée par les organisateurs prend tout son sens. Solange Lefebvre et Céline Béraud placent la question générationnelle au cœur de leur analyse portant respectivement sur le catholicisme québécois et français. Puis, l'émancipation des femmes catholiques est soulignée par Sylvie Couchepin, qui développe l'exemple du Valais romand dans les années 1960, et Béatrice Lebel, qui revient sur l'expérience de Boquen. Les mouvements catholiques constituent également un excellent prisme pour observer la crise des années 1960, comme le montrent les communications de Julien Fuchs sur les mouvements de jeunesse d'Alsace et de Consuelo Frauenfelder sur la JOC suisse. Enfin, Lorenzo Planzi, qui analyse l'évolution du clergé romand, et Frédéric Le Moigne, qui décrit l'effacement des évêques bretons, illustrent l'ébranlement de l'institution ecclésiale dans les années 1960-1975.

Le second axe de réflexion, plus culturel, explore l'évolution de la dimension identitaire des chrétientés occidentales. Il constitue un prolongement thématique et chronologique des travaux de Michel Lagrée sur les «parlers de la foi » et révèle avec force et originalité la décomposition des chrétientés étudiées. On y retrouve les stimulantes contributions d'Alain Gérard sur la Vendée, de Francis Python sur la Suisse romande, de Jan de Maeyer et Koen Abts sur la Belgique, de Louise Fuller sur l'Irlande, de Maurilio Guasco sur l'Italie du Nord et de Xavier Itçaina sur le Pays basque, qui décrivent chacun l'évolution des liens entre catholicisme et identité nationale ou régionale sur leur territoire. La Bretagne, déjà étudiée dans le Requiem déjà cité, est pour sa part évoquée à travers l'utopie des scouts Bleimor, sur laquelle revient Lionel Christien.

L'ouvrage se prolonge par deux communications sur la bande dessinée, dont l'ajout n'est en rien artificiel. Au contraire, elles apportent une vraie plus-value scientifique et séduiront un large public. Tant le regretté Jean-Christophe Cassard, qui montre comment le neuvième art révèle « l'effritement de la christianitude bretonne » que Fabrice Bouthillon, qui analyse les albums de Tintin avec virtuosité, offrent un magnifique miroir de la décomposition de la chrétienté tout en empruntant un chemin rarement suivi dans l'historiographie.

La publication s'achève par deux réflexions conclusives destinées à prolonger les débats : tandis qu'André Rousseau revient sur la situation actuelle de l’Église catholique en France, notamment en discutant le concept d' « exculturation » cher à Danièle HervieuLéger, Christian Sorrel clôt l'ouvrage par une synthèse intitulée " penser les ruptures ». Ruptures qui apparaissent en effet clairement au terme des deux jours de discussion et des 388 pages du recueil d'actes, tant sur le plan strictement religieux que sur le plan culturel. Les communications proposées jettent un regard novateur sur la déstabilisation des chrétientés occidentales, soulignant le rôle central des clercs, des militants catholiques et des femmes dans ces évolutions ainsi que l'importance du clivage générationnel et de la crise de la transmission. Dans tous les bastions étudiés, l'effondrement emprunte des voies parallèles suivant une chronologie proche. Les premiers craquements se font sentir dans les 
années 1950, surtout au Québec, puis les années 1960-1970 sont celles de l'ébranlement. Un nouveau paysage religieux émerge alors et le lien entre catholicisme et identité se distend. Plusieurs contributions laissent entrevoir au tournant du siècle l'existence d'un second seuil marqué par le progrès de l'indifférence, une hypothèse que le recul et des études plus spécifiques permettront d'affiner. Elles laissent aussi deviner que la décomposition n'est pas qu'un effacement mais également une recomposition. Ce sont précisément ces rénovations et ces germinations qui doivent constituer le thème central d'un troisième colloque, attendu à Lyon, et dont l’organisation s'impose.

Samuel GicQueL 